\title{
Ex Vivo Lung Perfusion of Cardiac-death Donor Lung in Pigs
}

Department of Thoracic and Cardiovascular Surgery, Severance Hospital ${ }^{1}$, Department of Thoracic and Cardiovascular Surgery, Gangnam Severance Hospital ${ }^{2}$, Division of Pulmonology, Department of Internal Medicine, Severance Hospital ${ }^{3}$, Yonsei University College of Medicine, Seoul, Korea

\section{Hyo Chae Paik, M.D. ${ }^{1}$, Seok Jin Haam, M.D. ${ }^{2}$, Moo Suk Park, M.D. ${ }^{3}$ and Joo Han Song, M.D. ${ }^{3}$}

Background: Lung transplantation (LTx) is a life-saving treatment for patients with end-stage lung disease; however, the shortage of donor lungs has been a major limiting factor to increasing the number of LTx. Growing experience following LTx using donor lungs after cardiac death (DCD) has been promising, although concerns remain. The purpose of this study was to develop a DCD lung harvest model using an ex vivolung perfusion (EVLP) system and to assess the function of presumably damaged lungs harvested from the DCD donor in pigs.

Methods: The $40 \mathrm{~kg}$ pigs were randomly divided into the control group with no ischemic lung injury ( $\mathrm{n}=5$ ) and the study group $(n=5)$, which had 1 hour of warm ischemic lung injury after cardiac arrest. Harvested lungs were placed in the EVLP circuit and oxygen capacities (OC), pulmonary vascular resistance (PVR), and peak airway pressure (PAP) were evaluated every hour for 4 hours. At the end of EVLP, specimens were excised for pathologic review and wet/dry ratio.

Results: No statistically significant difference in OC ( $P=0.353)$, PVR $(P=0.951)$, and PAP $(P=0.651)$ was observed in both groups. Lung injury severity score (control group vs. study group: $0.700 \pm 0.303$ vs. $0.870 \pm 0.130 ; P=0.230$ ) and wet/dry ratio (control group vs. study group: $5.89 \pm 0.97$ vs. $6.20 \pm 0.57 ; P=0.560$ ) also showed no statistically significant difference between the groups. Conclusions: The function of DCD lungs assessed using EVLP showed no difference from that of control lungs without ischemic injury; therefore, utilization of DCD lungs can be a new option to decrease the number of deaths on the waiting list.

Key Words: Lung transplantation, Tissue donors, Organ preservation, Warm ischemia 중심 단어: 폐이식, 장기기증, 장기보존, 온열허혈

\section{INTRODUCTION}

Lung transplantation (LTx) is a well-known life-saving therapy for many end-stage lung diseases. The utilization rate of the donor lungs are reported as low as 6.7\%(1), and low rate of utilization is responsible for the increased mortality of the patients on the waiting lists(2). There has been

Received March 3, 2014

Revised June 27, 2014

Accepted June 27, 2014

Corresponding author: Hyo Chae Paik

Department of Thoracic and Cardiovascular Surgery, Severance Hospital, Yonsei University College of Medicine, 50-1 Yonsei-ro, Seodaemun-gu, Seoul 120-752, Korea

Tel: 82-2-2228-2140, Fax: 82-2-393-6012

E-mail: hcpaik@yuhs.ac some strategies to increase the number of LTx around the world which include expanding the use of extended donor criteria(3), living donor lobar LTx(4), ex vivo lung perfusion (EVLP)(5), and use of lungs donated after cardiac death (DCD) (6-8). Among these strategies, use of DCD lungs is gradually getting the spotlight to resolve the problem of donor lung shortage although the use of DCD lungs may lead to higher prevalence of primary graft dysfunction, bronchiolitis obliterans, and mortality compared with using a heart beating donor lungs(6).

Kootstra et al.(7) classified DCD into four categories according to so called Maastricht category. Category I (dead on arrival to the hospital) and II (failed resuscitation) correspond to uncontrolled donors. Category III (awaiting cardiac arrest) and IV (cardiac arrest in a brain death donor) corre- 
spond to controlled donors(7). When such DCD lungs are considered as donors, an issue of proper assessment of lung function is imperative. EVLP is a method to evaluate the lungs that are rejected due to poor blood gas $(5,8)$, or can be used to assess DCD lungs by measuring the hemodynamics and oxygenation capacity.

The purpose of this study was to assess the harvested lungs from DCD donor pig using EVLP and prepare for the future utilization of organs from DCD in human LTx.

\section{MATERIALS AND METHODS}

\section{Animal}

All surgical procedures and animal care were provided in accordance with the Laboratory Animals Welfare Act, the Guide for the Care and Use of Laboratory Animals, and the Guidelines and Policies for swine Survival Surgery provided by the Institutional Animal Care and Use Committee in Yonsei University Health System.

Ten 40 kg Yorkshire female pigs (XP bio, Seoul, Korea) were randomly divided into two groups. They were sedated with $5 \mathrm{mg} / \mathrm{kg}$ of Tiletamine/Zolazepam (Zoletil, Virbac, Carros, France) and $2 \mathrm{mg}$ Xylazine (Rompun, Bayer, Seoul, Korea) intramuscularly. Endotracheal intubation with $8 \mathrm{~mm}$ diameter tube and foley catheter was inserted. Pigs were anesthetized with isoflurane (Forane, JW Pharmaceutical, Seoul, Korea). The ventilator was set in a volume control mode with tidal volume of $10 \mathrm{~mL} / \mathrm{kg}$, positive end expiratory pressure (PEEP) of $5 \mathrm{cmH}_{2} \mathrm{O}$, respiratory rate of $16 \sim 18$ breaths per minute, and $\mathrm{FiO}_{2} 1.0$ until the time of cardiac arrest.

In control group $(n=5)$, the lungs had no ischemic injury. After sternotomy, pericardium is opened and 15,000 $\mathrm{U}$ of heparin (JW Pharmaceutical) was injected into the main pulmonary artery (MPA). A purse string suture was made in the MPA with Prolene 4-0 (Ethicon, Peterborough, ON, Canada) and a 20 Fr. foley catheter was inserted. After ligating superior and inferior vena cava, aorta was cross clamped and left atrial (LA) appendage incised as the $4^{\circ} \mathrm{C}$ Perfadex preservation solution (Vitrolife, Göteborg, Sweden) $60 \mathrm{~mL} / \mathrm{kg}$ was flushed into MPA from the height of $30 \mathrm{~cm}$. After the flushing, heart was excised and retrograde perfusion with $500 \mathrm{~mL}$ of Perfadex into the left atrium. While maintaining airway pressure to $15 \mathrm{cmH}_{2} \mathrm{O}$ and $\mathrm{FiO}_{2}$ of 0.5 , the trachea was clamped and the lungs were excised. LA cuff was designed to match with the size of the funnel shaped LA cannula (Vitrolife). and was sutured with Prolene 4-0, and pulmonary artery (PA) cannula (Vitrolife AB) was inserted into MPA and tied with heavy silk (Ethicon). Tracheal tube was inserted in the airway avoiding the collapse of the lungs.

In the study group $(n=5)$, a vertical subxiphoid incision was made after the animal was anesthetized and atrial fibrillation was induced by $9 \mathrm{~V}$ electrical shock and waited for the cardiac arrest. After 1 hour of cardiac death, a sternum and pericardium was opened and 15,000 U of heparin was injected into MPA and cardiac massage was performed to circulate heparin. The following procedures were same as in the control group.

\section{Preparation of EVLP system}

The EVLP system consists of mechanical ventilator (Hamilton-C2, Hamilton Medical AG, Bonaduz, Switzerland) and centrifugal pump (Rotaflow, Maquet Cardiopulmonary AG, Hirrlingen, Germany) to circulate the perfusate. Mixed gas (6\% oxygen, $8 \% \mathrm{CO}_{2}, 86 \%$ nitrogen gas) was supplied as the perfusate passed through the membrane oxygenator (Quadrox PLS oxygenator, Maquet Cardiopulmonary AG) to deoxygenate before the perfusate is recirculated into the PA. Leukofilter was placed immediately before entering the PA and heat exchanger (HU 35, Maquet Cardiopulmonary AG) was connected to the membrane oxygenator (Fig. 1).

The perfusate used was $1,500 \mathrm{~mL}$ of Steen solution (Vitrolife $\mathrm{AB}$ ) mixed with 10,000 U heparin (JW Pharmaceutical), $500 \mathrm{mg}$ cefazolin (Yuhan Corp., Seoul, Korea), and $500 \mathrm{mg}$ of methylprednisolone (Dong-A pharmaceutical, Seoul, Korea).

\section{Management of EVLP system}

Harvested lungs were placed in a specially designed chamber (XVIVO chamber, Vitrolife AB) and both PA and LA cannula were connected to the system avoiding the air in the circulation. Circulation was started slowly with 150 $\mathrm{mL} / \mathrm{min}$ at $20^{\circ} \mathrm{C}$, and was slowly increased to perfusate temperature of $37^{\circ} \mathrm{C}$ over a period of 30 minutes. After 20 minutes of circulation, ventilation was started and perfusion flow was gradually increased. At the same time, $0.5 \mathrm{~L} / \mathrm{min}$ 


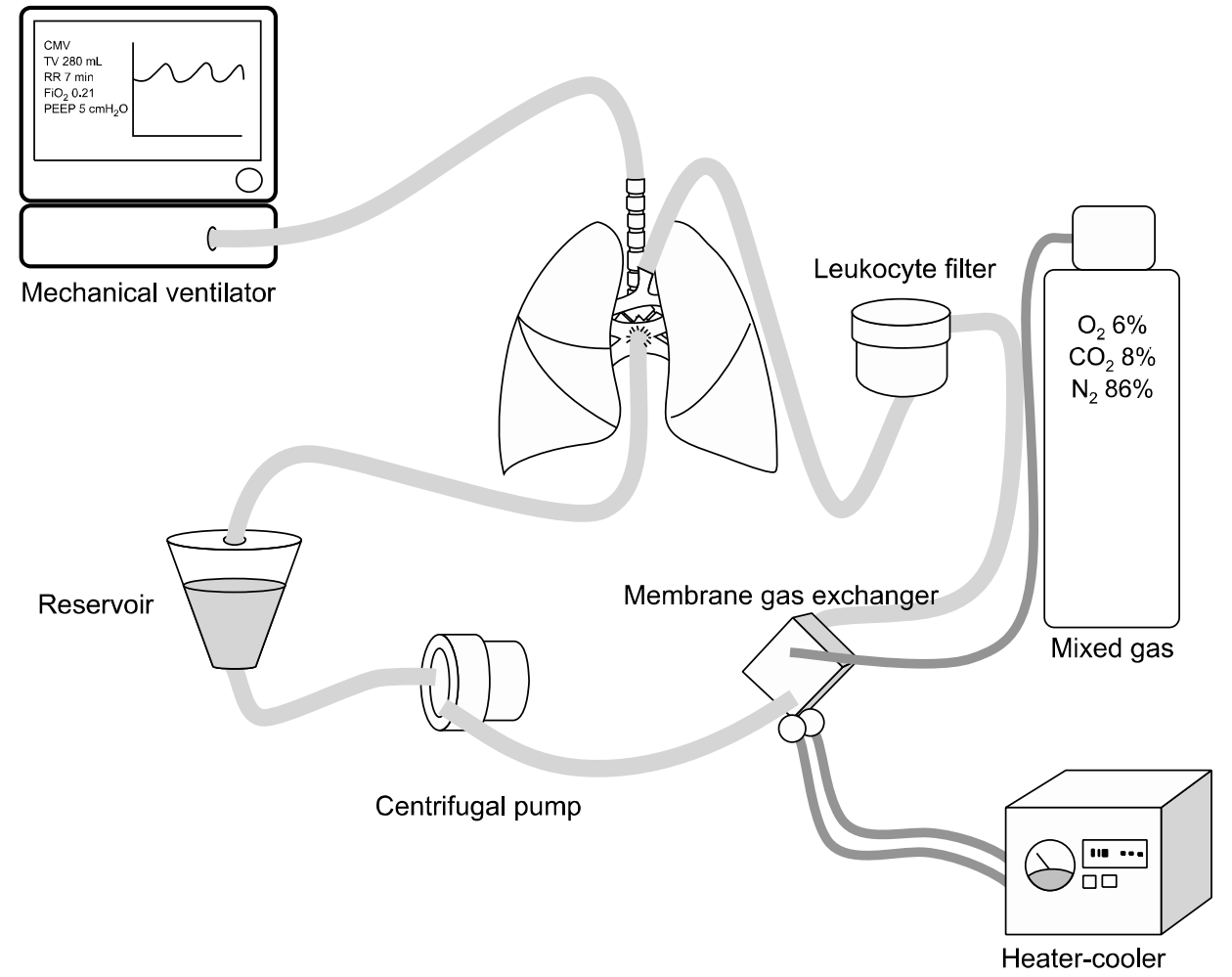

Fig. 1. Schematic diagram of $e x$ vivo lung perfusion (EVLP) model. EVLP system consists of mechanical ventilator, centrifugal pump, heatexchanger, and the perfusate deoxygenate as it passes through the membrane gas exchanger. Perfusate is infused into pulmonary artery through leukocyte depletion filter and stored in a hardshell reservior. Perfusate in the reservoir circulates continuously by the centrifugal pump. of mixed gas was insufflated to the membrane oxygenator, and gas flow was adjusted to maintain $\mathrm{PCO}_{2}$ between 35 and $45 \mathrm{mmHg}$. As the perfusate temperature reached $37^{\circ} \mathrm{C}$ and cardiac output of $40 \%$ expected, perfusion flow was increased upto $1,500 \mathrm{~mL} / \mathrm{min}$. Ventilator setting was as following; tidal volume of $7 \mathrm{~mL} / \mathrm{kg}$, respiration rate of 7 breaths per minute, PEEP of $5 \mathrm{cmH}_{2} \mathrm{O}$, and $\mathrm{FiO}_{2}$ of 0.21 . During the entire period of EVLP, LA pressure was maintained between 3 5 mmHg and PA pressure between 10 $15 \mathrm{mmHg}$ and this was possible by adjusting the level of the reservoir. To maintain the contents of the perfusate as constant as possible, $100 \mathrm{~mL}$ of Steen solution was exchanged every hour for a total of $500 \mathrm{~mL}$ during the experiment.

\section{Evaluation of the EVLP lungs}

The initial time of the evaluation was set to a point when the cardiac output reached $40 \%$ and then measured every hour by measuring the functional parameters. Ten minutes prior to measurement, recruitment maneuver was done twice to an airway pressure of $25 \mathrm{mmHg}$ to avoid atelectasis in $\mathrm{FiO}_{2}$ 1.0.

Measured parameters were oxygen capacity ([LA perfusate $\mathrm{PO}_{2}-\mathrm{PA}$ pefusate $\left.\mathrm{PO}_{2}\right] / \mathrm{FiO}_{2}[\mathrm{mmHg}]$ ) calculated using arterial blood gas analysis, pulmonary vascular resistance (PVR) ([PA pressure-LA pressure] $\times 80 / \mathrm{PA}$ flow [dynes • $\left.\left.\mathrm{sec} / \mathrm{cm}^{5}\right]\right)$, and peak airway pressure (PAP) $\left(\mathrm{cmH}_{2} \mathrm{O}\right)$.

After 4 hours of EVLP, lung specimen from anterior and posterior portion of right lower lobe was resected for the pathologic evaluation. The specimens were fixed in $10 \%$ buffered formalin and stained by hematoxylin and eosin (H\&E). Lung injury severity (LIS) was scored according to alveolar capillary congestion, hemorrhage, infiltration, or aggregation of neutrophils in the air space or the vessel wall, and thickness of the alveolar wall/hyaline membrane formation. Each component was graded on a scale from 0 (minimal damage) to 4 (maximal damage). The average sum of each field score was compared among groups(9).

Wet/dry weight ratio was examined by weight difference before and after storage in $80^{\circ} \mathrm{C}$ oven for 72 hours. 


\section{Statistics}

For comparison of the functional parameters such as oxygen capacity, PVR, and PAP, a repeated measures analysis of variance was performed. For comparison of wet/dry ratio and LIS, a Mann-Whitney test was performed. $P$-value less than 0.05 was considered statistically significant.

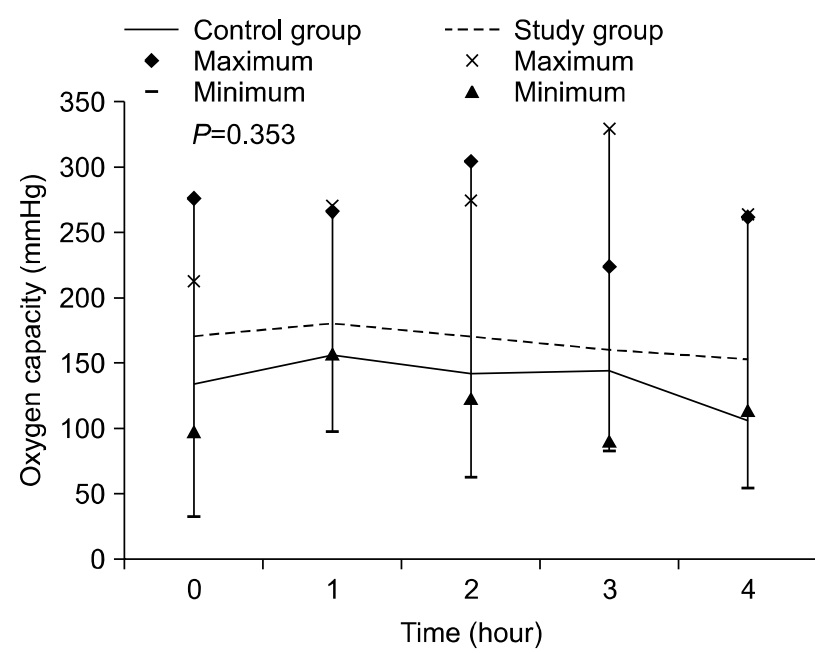

Fig. 2. Comparison of oxygen capacities during 4 hours of ex vivo lung perfusion (EVLP). The level of oxygen capacity was higher in the study group than in the control group during the 4 hours of EVLP.

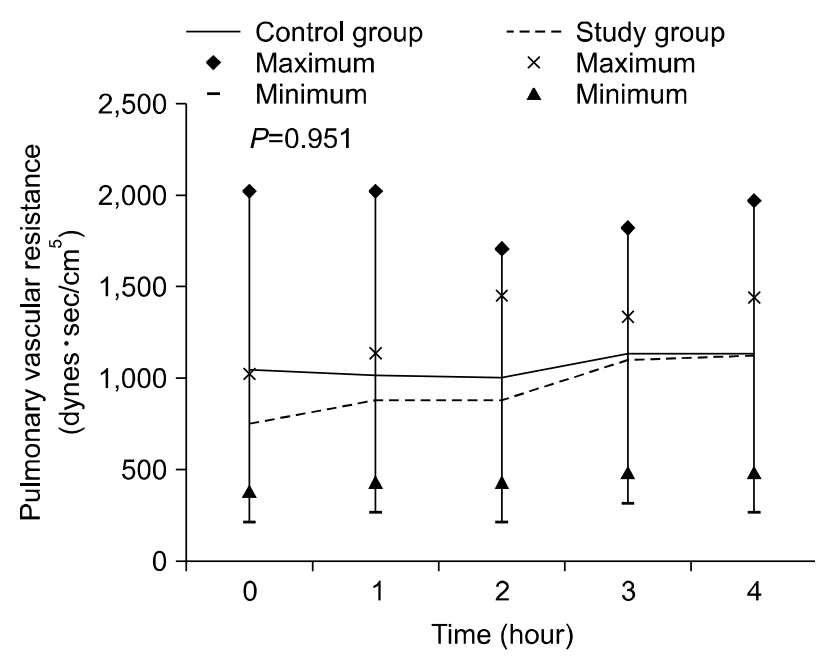

Fig. 3. Comparison of pulmonary vascular resistances during 4 hours of ex vivo lung perfusion (EVLP). Pulmonary vascular resistance was higher in the control group, although it did not show statistically significant difference. As the EVLP prolonged, pulmonary vascular resistance slightly increased, which was more apparent in the study group.

\section{RESULTS}

The level of oxygen capacity was higher in the study group than in control group every hour, but it was statistically insignificant throughout 4 hours period $(P=0.353)$. Over time, the levels of oxygen capacity gradually decreased but remained relatively stable during the entire period of EVLP in both groups (Fig. 2).

PVR was higher overall in the control group than in the study group, but this also did not show a statistically significant difference $(P=0.951)$. As time went by, PVR had a tendency to increase slightly, which was more apparent in the study group (Fig. 3).

During the 4 hours assessment period, the PAP in the study group was always higher than the control group, but did not show statistically significant difference $(P=0.651)$. For the first 2 hours during EVLP, the PAPs in both groups remained stable, but increased sharply thereafter (Fig. 4).

LIS was $0.700 \pm 0.303$ in control group and $0.870 \pm 0.130$ in study group, with no statistically significant difference $(P=0.230)$. Wet/dry ratio was $5.89 \pm 0.97$ in the control group and $6.20 \pm 0.57$ in the study group, but these values also did not statistically significant difference $(P=0.560)$.

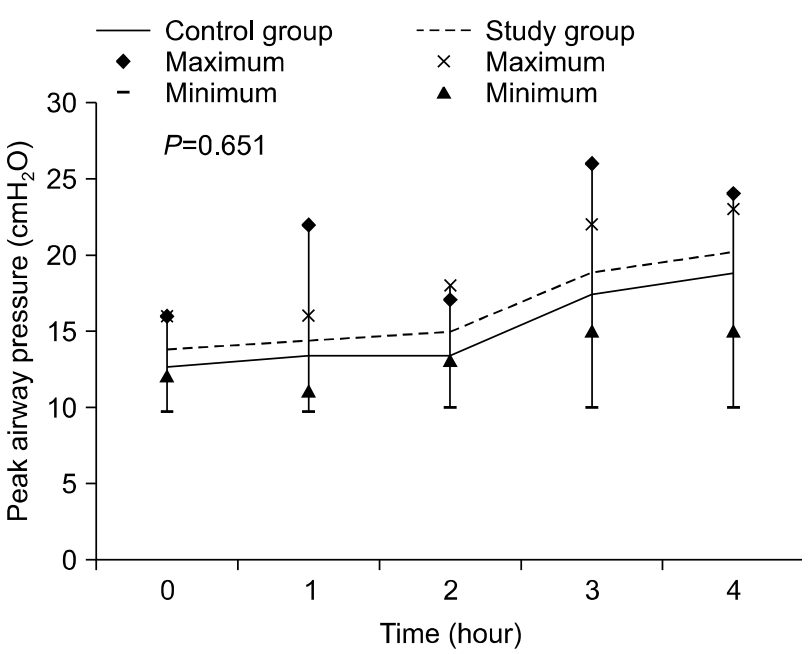

Fig. 4. Comparison of peak airway pressure during 4 hours of ex vivo lung perfusion (EVLP). The peak airway pressure of in the study group was higher during the entire period of EVLP but did not show statistically significant difference. The peak airway pressures in both groups increased sharply after 2 hours, which suggested progression of pulmonary edema. 


\section{DISCUSSION}

Donation after brain death (DBD) has traditionally provided all lungs for LTx. However, since the number of donor lungs are far below the numbers on the waiting list, the lung transplant professionals must explore donation from a marginal donors(3) or $\operatorname{DCD}(10,11)$. The lungs harvested from $\mathrm{DBD}$ have a high chance of lung injury from the process of brain death or from the prolonged intensive care prior to organ harvest, and the marginal donor lungs may lead to higher incidence of ischemia-reperfusion injury, accounting for as high as $30 \%$ during the perioperative peri$\operatorname{od}(12)$.

Since the first nonheart-beating donor lung was successfully transplanted in human after intrapleural topical cooling(10), the United Network for Organ Sharing presented a short-term outcomes of LTx from DCD donors from 2004 to 2009, and concluded that DCD lung recipient's survival rates were not much different than the survival rates from brain dead donors(13). Snell et al.(14) reported acceptable early outcomes with a mean survival time of 311 days in controlled DCD lungs that were transplanted, and De Oliveira et al.(11) reported a long-term outcomes of all DCD donor lungs from 1993 to 2009, and showed equal survival rates from DCD donors to that from brain dead donors. However, a concern that DCD lung may be inferior to that of brain dead donors have been a barrier in increasing the number of transplantation from the DCD donors. Another barrier to DCD lungs is a concept that DCD lungs should undergo evaluation of the lungs by EVLP assessment prior to deciding $\operatorname{LTx}(5)$. A great portion of lungs harvested from DCD lungs might be in a similar status as to a brain dead donor lungs but the concept that they should be evaluated with the means of EVLP assessment hinder them from being more frequently used.

EVLP not only allows a visual inspection of the explanted lungs, but it can measure hemodynamic and aerodynamic data, and gas exchange capacity(15). Another important advantage is that during the normothermic perfusion, active metabolic function is maintained, which provides an opportunity for continued assessment of the organ during the EVLP, or have a chance to recover with the help of antioxidants(16) or gene transfer factors(17) that have effect during the warm perfusion. Cypel et al.(18) have developed a strategy of EVLP that allowed optimal PVR, airway pressure, and oxygen capacity throughout the 12-hour preservation period. However, Mason et al.(19) has shown excellent early graft function using DCD lungs that were not placed on EVLP and therefore, advocated expanded usage of DCD lungs without routine use of EVLP. In this study, functional variables such as oxygen capacity, PVR, and PAP revealed no difference between the two groups. Although LIS and wet/dry ratio were higher in the study group, lung function remained similar to the heart beating donor lungs.

The most common postoperative complication immediately following LTx from brain death donor is graft dysfunction as it may also be the same for the DCD lungs. However, experimental evidence has shown less chance of ischemia-reperfusion injury in DCD lungs(20) as demonstrated by high $\mathrm{PO}_{2} / \mathrm{FiO}_{2}$ ratio and a low primary graft dysfuction scores.

The relationship between the incidence of airway complications and bronchiolitis obliterans syndrome (BOS) is not yet certain due to the limited experience with the DCD LTx(6), and a novel strategies in the future study include premortem treatment of DCD donors with $\mathrm{N}$-acetyl cysteine, surfactant, nitroglycerin, or nitric oxide just prior to implantation and compare the incidence of ischemia reperfusion injury and the incidence of BOS during the follow-up period(16). As the legal issue of providing the recipients with the DCD lungs is solved, more patients can be saved as shown by the report that using the DCD donors has increased the number of LTx by $16 \%$ beyond the DBD LTx performed over the same period(14).

\section{CONCLUSION}

Our findings suggest that the utilization of lungs from DCD after the assessment by EVLP can expand the donor pool for LTx, and DCD lung donation can be a new option to decrease the number of death on the waiting list. However, further studies with the large animals are necessary in order to apply the actual LTx using DCD donor lungs in humans. 


\section{ACKNOWLEDGEMENTS}

This study was supported by a special grant from the Dean of Yonsei University College of Medicine for 2012.

\section{REFERENCES}

1) Paik HC, Haam SJ, Lee DY, Yi GJ, Song SW, Kim YT, et al. Donor evaluation for lung transplantation in Korea. Transplant Proc 2012;44:870-4.

2) De Meester J, Smits JM, Persijn GG, Haverich A. Listing for lung transplantation: life expectancy and transplant effect, stratified by type of end-stage lung disease, the Eurotransplant experience. J Heart Lung Transplant 2001;20:518-24.

3) Botha P, Trivedi D, Weir CJ, Searl CP, Corris PA, Dark $\mathrm{JH}$, et al. Extended donor criteria in lung transplantation: impact on organ allocation. J Thorac Cardiovasc Surg 2006;131:1154-60.

4) Date H. Update on living-donor lobar lung transplantation. Curr Opin Organ Transplant 2011;16:453-7.

5) Cypel M, Yeung JC, Liu M, Anraku M, Chen F, Karolak $\mathrm{W}$, et al. Normothermic ex vivo lung perfusion in clinical lung transplantation. N Engl J Med 2011;364:1431-40.

6) Wigfield $\mathrm{CH}$, Love RB. Donation after cardiac death lung transplantation outcomes. Curr Opin Organ Transplant 2011;16:462-8.

7) Kootstra G, Daemen JH, Oomen AP. Categories of nonheart-beating donors. Transplant Proc 1995;27:2893-4.

8) Ingemansson R, Eyjolfsson A, Mared L, Pierre L, Algotsson L, Ekmehag B, et al. Clinical transplantation of initially rejected donor lungs after reconditioning ex vivo. Ann Thorac Surg 2009;87:255-60.

9) Fang WF, Cho JH, He Q, Lin MC, Wu CC, Voelkel NF, et al. Lipid A fraction of LPS induces a discrete MAPK activation in acute lung injury. Am J Physiol Lung Cell Mol Physiol 2007;293:L336-44.

10) Steen S, Sjöberg T, Pierre L, Liao Q, Eriksson L, Algotsson L. Transplantation of lungs from a non-heart-beating donor. Lancet 2001;357:825-9.
11) De Oliveira NC, Osaki S, Maloney JD, Meyer KC, Kohmoto T, D'Alessandro AM, et al. Lung transplantation with donation after cardiac death donors: long-term follow-up in a single center. J Thorac Cardiovasc Surg 2010;139:1306-15.

12) Christie JD, Edwards LB, Kucheryavaya AY, Benden C, Dipchand AI, Dobbels F, et al. The Registry of the International Society for Heart and Lung Transplantation: 29th adult lung and heart-lung transplant report-2012. J Heart Lung Transplant 2012;31:1073-86.

13) United Network for Organ Sharing (UNOS). Donation after cardiac death (DCD) lung donors transplant outcomes [Internet]. Richmond: UNOS; 2010 [cited 2014 Mar 3]. Available from:

http://www.unos.org/about/index.php?topic=newsroom\&article_id=2631.

14) Snell GI, Levvey BJ, Oto T, McEgan R, Pilcher D, Davies A, et al. Early lung transplantation success utilizing controlled donation after cardiac death donors. Am J Transplant 2008;8:1282-9.

15) Steen S, Liao Q, Wierup PN, Bolys R, Pierre L, Sjöberg T. Transplantation of lungs from non-heart-beating donors after functional assessment ex vivo. Ann Thorac Surg 2003;76:244-52.

16) Rega FR, Wuyts WA, Vanaudenaerde BM, Jannis NC, Neyrinck AP, Verleden GM, et al. Nebulized N-acetyl cysteine protects the pulmonary graft inside the non-heartbeating donor. J Heart Lung Transplant 2005;24:1369-77.

17) Cypel M, Liu M, Rubacha M, Yeung JC, Hirayama S, Anraku $\mathrm{M}$, et al. Functional repair of human donor lungs by IL-10 gene therapy. Sci Transl Med 2009;1:4ra9.

18) Cypel M, Yeung JC, Hirayama S, Rubacha M, Fischer S, Anraku M, et al. Technique for prolonged normothermic ex vivo lung perfusion. J Heart Lung Transplant 2008;27: 1319-25.

19) Mason DP, Brown CR, Murthy SC, Vakil N, Lyon C, Budev $\mathrm{MM}$, et al. Growing single-center experience with lung transplantation using donation after cardiac death. Ann Thorac Surg 2012;94:406-11.

20) Neyrinck AP, Van De Wauwer C, Geudens N, Rega FR, Verleden GM, Wouters P, et al. Comparative study of donor lung injury in heart-beating versus non-heart-beating donors. Eur J Cardiothorac Surg 2006;30:628-36. 